\title{
Effect of Molecular Weight on Cloud Point of Aqueous Solution of Poly (ethylene oxide)- Poly (propylene oxide) Alternating Multiblock Copolymer
}

\author{
Tasuku Horiuchi ${ }^{1}$, Kazuaki Rikiyama ${ }^{1}$, Kenji Sakanaya ${ }^{2}$, Yusuke Sanada ${ }^{2}$, \\ Keisuke Watanabe ${ }^{2}$, Misako Aida ${ }^{1}$, and Yukiteru Katsumoto ${ }^{2 *}$ \\ ${ }^{1}$ Department of Chemistry, Graduate School of Science, Hiroshima University, 1-3-1 Kagamiyama, Higashi-hiroshima 739-8526, JAPAN \\ ${ }^{2}$ Department of Chemistry, Faculty of Science, Fukuoka University, 8-19-1 Nanakuma, Jonan-ku, Fukuoka 814-0180, JAPAN
}

\begin{abstract}
A poly(ethylene oxide) (PEO)-poly(propylene oxide) (PPO) alternating multiblock (AMB) copolymer with various molecular weights was prepared via precipitation fractionation from an acetone/ $n$ hexane mixture. The cloud point $\left(T_{\mathrm{c}}\right)$ of the aqueous solution of PEO-PPO AMB copolymer decreased as the number-average molecular weight of the sample increased. This phenomenon is generally observed for certain homopolymer systems having a lower critical solution temperature, such as PEO/water and $\operatorname{poly}\left(N, N\right.$-diethylacrylamide)/water systems. The relationship between the $T_{\mathrm{c}}$ of the solutions and the number of monomer units of the AMB copolymer suggests that the Shultz-Flory theory is applicable to this system.
\end{abstract}

Key words: multiblock copolymer, thermo-responsive, phase separation, molecular weight dependence

\section{Introduction}

Thermoresponsive polymers are a class of smart materials. The properties of such polymers change significantly in a controlled fashion under the influence of external stimuli $^{1}$. To develop synthetic polymer systems that act as protein mimics is a great challenge for polymer scientists. The block design of copolymers is an effective strategy for preparing protein mimics using synthetic polymers ${ }^{2}$. An alternative way is to control the monomer sequence, which corresponds to the primary structure of proteins ${ }^{3)}$. However, the interaction among the monomers often makes it difficult to predict the macroscopic properties of the final products ${ }^{4,5)}$. In comparison with monomer sequence control, the block design is advantageous for achieving predictable physicochemical properties of the resultant copolymer and scale-up of the preparation process. Because the individual blocks in the copolymer may retain the characteristics of the homopolymer, the numerous reports on the homopolymers may serve as a block library ${ }^{6-19)}$.

Recently, we investigated the solution properties of amphiphilic alternating multiblock (AMB) copolymers. The AMB copolymer of poly (ethylene oxide) (PEO) and poly (propylene oxide) (PPO), i.e., the PEO-PPO AMB copolymer, exhibits amphiphilic features comparable to those of
Pluronic and Ploxamer. Unique characteristics of the AMB configuration were observed for the unimer morphology in water. Previously, we found that the unimer of PEO-PPO AMB copolymers in water forms a core-corona structure similar to flower micelles ${ }^{20)}$. This may arise from two factors: the hydrophobic interaction among the PPO blocks in the core and the repulsion among the unimers based upon stabilization of the PEO chain at the corona. When the hydrophilic interaction was not sufficiently strong, the unimer of the AMB copolymers could not form a core-corona structure. Indeed, the AMB copolymer of PEO and poly ( $N$-ipropylacrylamide) (PNiPAm) adopts a random-coil conformation in water at room temperature, because PNiPAm tends to be well hydrated compared with $\mathrm{PPO}^{2)}$. Because the PPO blocks are sufficiently hydrophobic to form a unimer micelle, the PEO-PPO AMB copolymer can also be expected to serve as a simple model of multipass transmembrane proteins such as bacteriorhodopsin ${ }^{21)}$.

Although the PEO-PPO AMB copolymers possess interesting features as above mentioned, the fundamental aspects have yet to be fully revealed. In this study, we focus on the effect of the molecular weight on the cloud point $\left(T_{\mathrm{c}}\right)$ of the copolymers. Based on the literature concerning PEO-PPO-PEO triblock copolymers ${ }^{22)}$, the hydro-

\footnotetext{
*Correspondence to: Yukiteru Katsumoto, Department of Chemistry, Faculty of Science, Fukuoka University, 8-19-1 Nanakuma, Jonan-ku, Fukuoka 814-0180, JAPAN

E-mail: katsumoto@fukuoka-u.ac.jp

Accepted February 8, 2020 (received for review January 28, 2020)

Journal of Oleo Science ISSN 1345-8957 print / ISSN 1347-3352 online

http://www.jstage.jst.go.jp/browse/jos/ http://mc.manusriptcentral.com/jjocs
} 
phobicity of PEO-PPO block copolymers is essentially proportional to the molecular weight of $\mathrm{PEO}$ and $\mathrm{PPO}$ when the weight fraction of $\mathrm{PEO}\left(f_{\mathrm{PEO}}\right)$ is constant. For the $\mathrm{AMB}$ copolymers, however, the molecular weight of the PEO and PPO blocks is fixed, but the number of PEO-PPO repeating pairs varies depending on the total molecular weight. Herein, PEO-PPO AMB copolymers with various molecular weights are prepared by precipitation fractionation. The fractionated samples are used to investigate the $T_{\mathrm{c}}$ of the aqueous solution.

\section{Experimental Procedures}

\subsection{Preparation of PEO-PPO AMB copolymer}

The PEO-PPO AMB copolymer was prepared by a dehydrated condensation reaction according to the literature ${ }^{23)}$. Briefly, $\alpha, \omega$-diamino PPO (JEFFAMINE D-2000; weight-average molecular weight $\left.\left(M_{\mathrm{w}}\right)=2,000\right)$ was kindly supplied by Huntsman Corporation. $\alpha, \omega$-Disuccinimidyl PEO (SUNBRIGHT DE-100HS; $\left.M_{\mathrm{w}}=10,000\right)$ was purchased from NOF Corporation. The reaction was carried out in chloroform solution at $0^{\circ} \mathrm{C}$. The crude sample was recovered by dialysis against water, followed by freeze-drying. Precipitation fractionation of the copolymer was performed by phase separation in an acetone $/ n$-hexane mixture at $25-50^{\circ} \mathrm{C}$. The PEO-PPO AMB copolymer prepared herein is denoted as $\left(\mathrm{EO}_{220} \mathrm{PO}_{33}\right)_{n}$, where $\mathrm{EO}$ is the ethylene oxide unit, $\mathrm{PO}$ is the propylene oxide unit, and $n$ is the number of PEO-PPO repeating units. The characterization details can be found in previous reports ${ }^{20,23)}$.

\subsection{Size exclusion chromatography (SEC)}

The SEC apparatus consisted of a Jasco Intelligent HPLC system equipped with a guard column (SB-G, Shodex), two separation columns (SB-802.5HQ and SB-806MHQ, Shodex), and a refractive index detector(RI-2031Plus, Jasco). $N, N$-Dimethylformamide (HPLC grade, Wako) with $10 \mathrm{mM} \mathrm{LiBr}$ was used as the eluent at a flow rate of 0.35 $\mathrm{mL} \mathrm{min}^{-1}$, at $60^{\circ} \mathrm{C}$. The number-average molecular weight $\left(M_{\mathrm{n}}\right), M_{\mathrm{w}}$, and the polydispersity $\left(M_{\mathrm{w}} / M_{\mathrm{n}}\right)$ were evaluated with respect to standard polystyrene samples with ten different peak-top molecular weights in the range of $1.22 \times$ $10^{3}$ to $2.70 \times 10^{6}$ (STANDARD SM-105, Shodex).

\section{3 ${ }^{1} \mathrm{H}$ NMR and IR spectroscopy}

The ratio of $\mathrm{EO}$ units to $\mathrm{PO}$ units $(E O / P O)$ in the PEO-PPO AMB copolymers was determined from the ${ }^{1} \mathrm{H}$ NMR spectra recorded on an Ascend 400 (Bruker)instrument at $400 \mathrm{MHz}$. All spectra were acquired at $25^{\circ} \mathrm{C}$ using $1.0 \mathrm{wt} \% \mathrm{D}_{2} \mathrm{O}$ solutions.

\subsection{Turbidity measurements}

The transmittance of $633 \mathrm{~nm}$ light through the polymer solution was monitored by using a UV-Vis spectrophotometer (V-630iRM, Jasco) equipped with a temperature controller(ETCS-761, Jasco). The sample was heated at a rate of $1.0^{\circ} \mathrm{C} \mathrm{min}{ }^{-1}$. The cloud point $\left(T_{\mathrm{c}}\right)$ was defined by referring to the first derivative of the transmittance curve.

\section{Results and Discussion}

\subsection{Characterization of the fractionated samples}

Figure 1 shows the SEC charts of the PEO-PPO AMB copolymers, $\left(\mathrm{EO}_{220} \mathrm{PO}_{33}\right)_{n}$, before and after precipitation fractionation. Two peaks at 2270 and $2330 \mathrm{~s}$ were apparent in the SEC chart of the last fraction. Thus, we did not analyze this sample (denoted as "residue" in Fig. 1). The SEC charts of fraction 1-3 showed a systematic shift, indicating differences in the $M_{\mathrm{n}}$ of each fraction. The estimated $M_{\mathrm{n}}$ and $M_{\mathrm{w}} / M_{\mathrm{n}}$ values are listed in Table 1. Although fractionation appeared to be successful based on the $M_{\mathrm{n}}$ of each fraction, the $M_{\mathrm{w}} / M_{\mathrm{n}}$ values were still large (1.7-2.4). In general, fractionation of copolymers is more difficult than fractionation of homopolymers because the solubility of copolymers is also influenced by their chemical composition $^{24)}$. To estimate the $E O / P O$ ratio for the fractionated samples, the ${ }^{1} \mathrm{H}$ NMR spectra were acquired (Fig. 2). The peak at $\delta=3.7 \mathrm{ppm}$ arises from the methylene proton of the $\mathrm{EO}$ and $\mathrm{PO}$ units, while the peak at $\delta=1.2 \mathrm{ppm}$ is due to the methyl proton of the PO unit. The intensity ratio of the $\delta=3.7 \mathrm{ppm}$ peak to the $\delta=1.2 \mathrm{ppm}$ peak $\left(I_{3.7} / I_{1.2}\right)$ was estimated to be 9.6-9.9. Because the PEO block contains

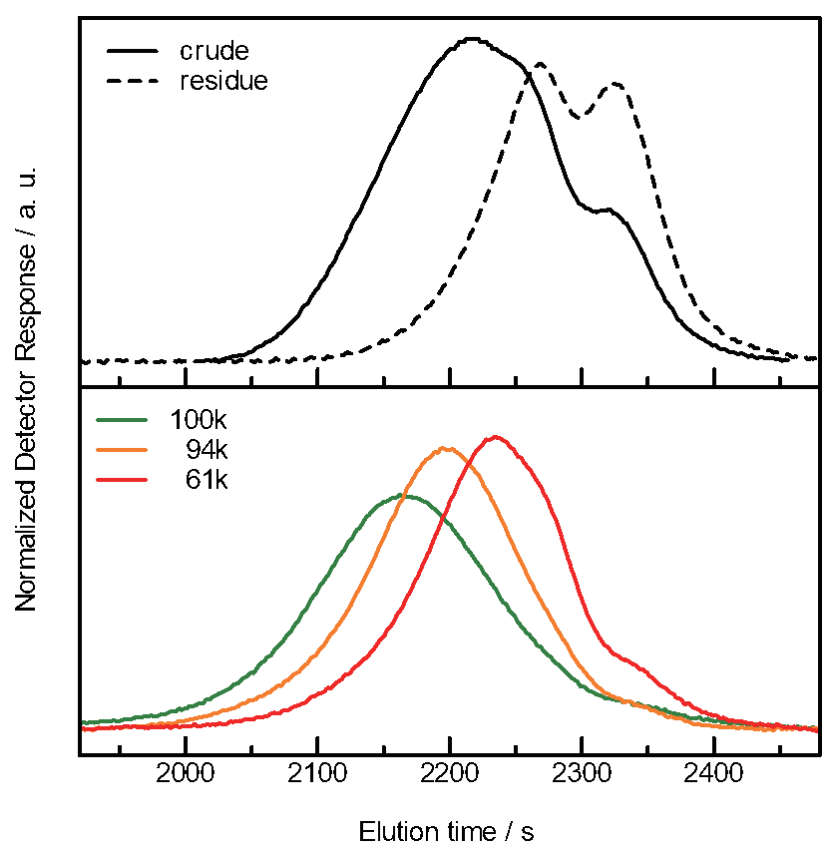

Fig. 1 SEC charts of the crude and each fractions of the PEO-PPO AMB copolymer. 
Table 1 Molecular weight $\left(M_{\mathrm{n}}\right)$, polydispersity $\left(M_{\mathrm{w}} / M_{\mathrm{n}}\right)$, the ratio of EO units to PO units $\left(I_{3.7} / I_{1.2}\right)$, and the number of repeating units $(n)$ of PEO-PPO AMB copolymers.

\begin{tabular}{ccccc}
\hline sample & fraction & $M_{\mathrm{n}}\left(M_{\mathrm{w}} / M_{\mathrm{n}}\right)^{\mathrm{a}}$ & $I_{3.7} / I_{1.2}{ }^{\mathrm{b}}$ & $n$ \\
\hline crude & - & $7.2 \times 10^{4}(3.3)$ & - & - \\
$120 \mathrm{k}^{\mathrm{c}}$ & - & $1.2 \times 10^{5}(1.5)$ & 9.4 & 6.3 \\
$100 \mathrm{k}$ & 1 & $1.0 \times 10^{5}(2.4)$ & 9.9 & 5.4 \\
$94 \mathrm{k}$ & 2 & $9.4 \times 10^{4}(1.7)$ & 9.6 & 5.1 \\
$61 \mathrm{k}$ & 3 & $6.1 \times 10^{4}(1.8)$ & 9.9 & 3.3 \\
\hline
\end{tabular}

${ }^{a}$ Size exclusion chromatography with polystyrene standards.

${ }^{\mathrm{b}}$ Integrated intensity ratio of the peak at $3.7 \mathrm{ppm}$ to $1.2 \mathrm{ppm}$ obtained from ${ }^{1} \mathrm{H}$ NMR.

${ }^{c}$ The fraction was obtained from a different lot.

220 EO units and the PPO block has 33 PO units, the oneby-one connection of PEO and PPO yields $I_{3.7} / I_{1.2}=9.5$. Thus, we can assume that the PEO-PPO AMB copolymers contain an equal amount of PEO and PPO blocks and the chemical composition of each fractionated sample is similar.

The SEC and ${ }^{1} \mathrm{H}$ NMR results indicate successful precipitation fractionation of the PEO-PPO AMB copolymer. The $n$ value for $\left(\mathrm{EO}_{220} \mathrm{PO}_{33}\right)_{n}$ was estimated to range from 3.3 to 5.4 . When $n$-hexane as a poor solvent was added to the acetone solution, the PEO-PPO AMB copolymers precipitated in the order of the molecular weight. Interestingly, this behavior is similar to the precipitation fractionation of homopolymers. Thus, we presumed that the EO/PO for a single chain did not differ in the PEO-PPO AMB copoly-

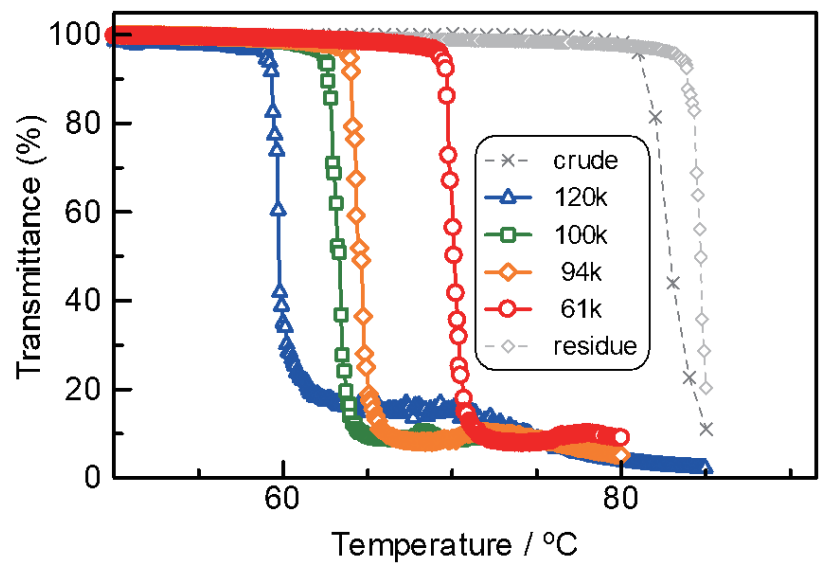

Fig. 3 Temperature dependence of the transmittance of the $633 \mathrm{~nm}$ light passing through the aqueous solution of the PEO-PPO AMB copolymers. The polymer concentration is $1.5 \mathrm{wt} \%$ except for the $120 \mathrm{k}$ fraction $(1.0 \mathrm{wt} \%)$.

mers prepared by amide condensation.

\subsection{Molecular weight dependence of $T_{\mathrm{c}}$ for the PEO-PPO AMB copolymer in water}

The results of the turbidity measurement for the copolymers are shown in Fig. 3. The $T_{\mathrm{c}}$ values were clearly high for the crude sample and the residue. As shown in Fig. 1, the residue contained a certain amount of impurity, corresponding to the peak at $2320 \mathrm{~s}$ in the SEC chart. The $T_{\mathrm{c}}$ of the crude sample may also contain a large contribution from the impurity. Thus, we assumed that there is a short PEO-PPO block copolymer in the crude sample and the

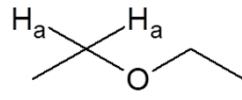

\section{$3.7 \mathrm{ppm}$}

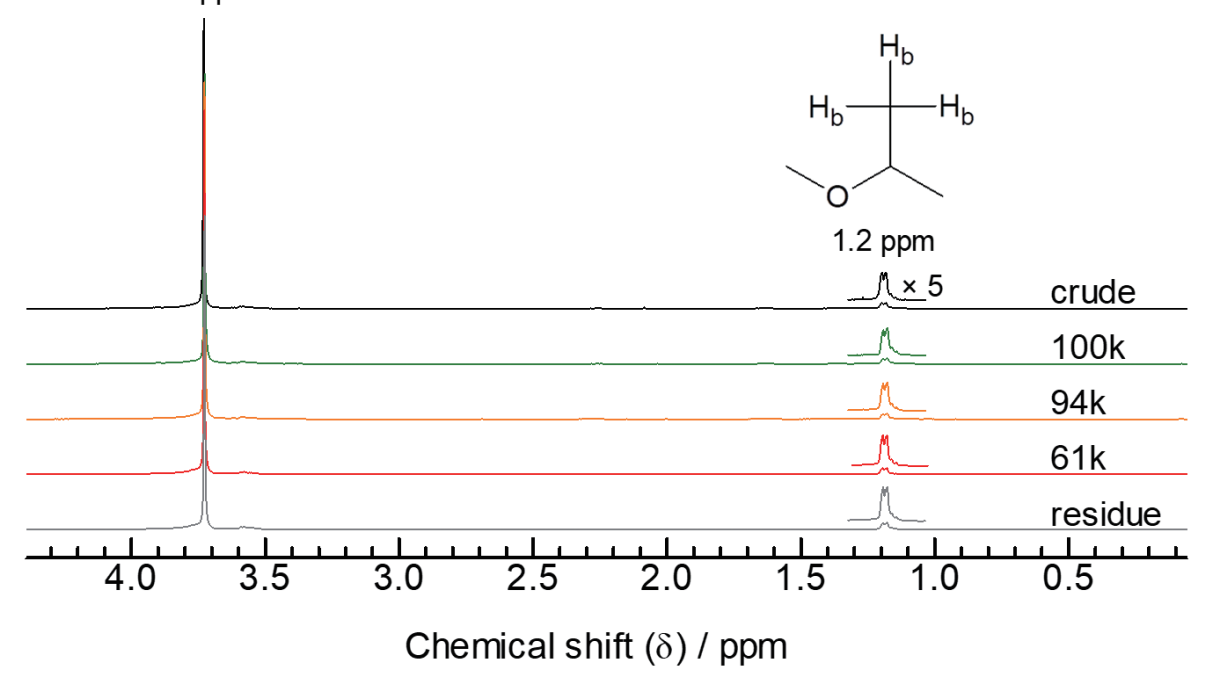

Fig. $2{ }^{1}$ H NMR spectra of the fractionated PEO-PPO AMB copolymers, the crude, and the residue. 


\section{T. Horiuchi, K. Rikiyama, K. Sakanaya et al.}

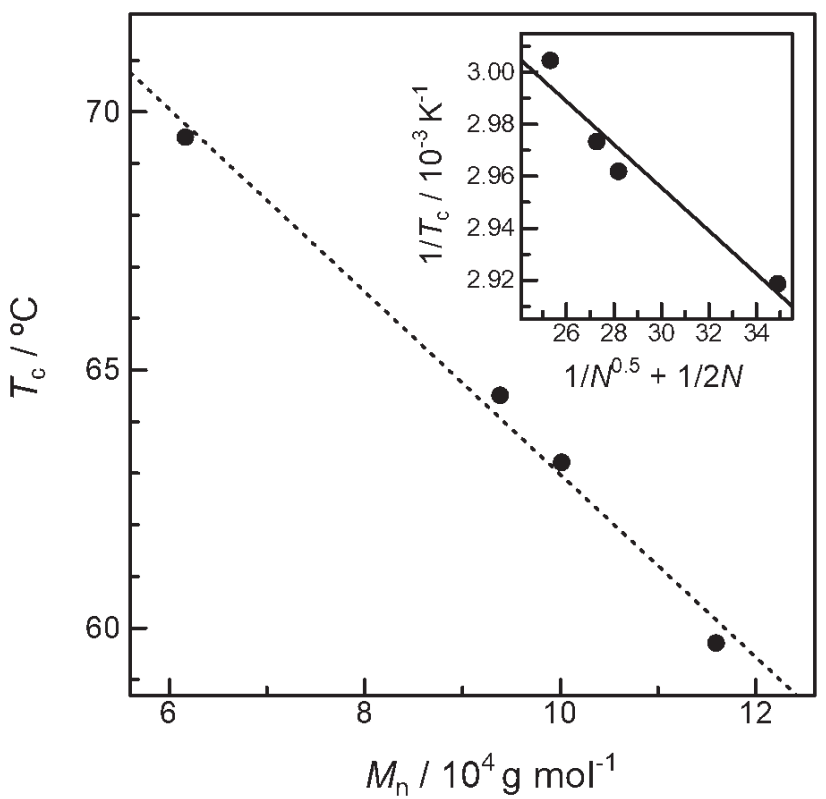

Fig. 4 Concentration dependence of the cloud point $\left(T_{\mathrm{c}}\right)$ for the aqueous solutions of each PEO-PPO AMB copolymer. The $T_{\mathrm{c}}$ is determined by the transmittance curve measured by the $633 \mathrm{~nm}$ light.

residue, resulting in the high $T_{\mathrm{c}}$. Note that the aqueous solution of the PEO homopolymer with $M_{\mathrm{n}}=14,000 \mathrm{~g} \mathrm{~mol}^{-1}$ undergoes phase separation around $107^{\circ} \mathrm{C}^{25)}$, whereas the $T_{\mathrm{c}}$ of an aqueous solution of Pluronic F88, for which the $E O / P O$ ratio is similar to that of $\left(\mathrm{EO}_{220} \mathrm{PO}_{33}\right)_{n}$ synthesized herein, is over $100^{\circ} \mathrm{C}^{26)}$.

Figure 4 shows the molecular weight dependence of $T_{\mathrm{c}}$ for the aqueous solution of the PEO-PPO AMB copolymers. The $T_{\mathrm{c}}$ decreased with increasing $M_{\mathrm{n}}$, which is typical for polymer solutions that undergo phase separation with a lower critical solution temperature (LCST), such as the $\mathrm{PEO} /$ water $^{25)}$ and poly $(N, N$-diethylacryladmide $) /$ water $^{27)}$ systems. On the other hand, poly ( $N$-isopropylacrylamide)/ water system, which is a quite popular system that undergoes LCST-type phase separation, shows an abnormal $M_{\mathrm{n}}$ dependence on $T_{\mathrm{c}}$, in which $T_{\mathrm{c}}$ decreases with decreasing $M_{\mathrm{n}}^{28)}$.

The inset of Fig. 4 shows the plot of $1 / T_{\mathrm{c}}$ against $1 / N^{0.5}+$ $1 / 2 N$, where $N$ is the number of monomer units (both of EO and $\mathrm{PO}$ ) in the AMB copolymer. According to the ShultzFlory theory ${ }^{29)}$, the critical solution temperature $\left(T_{\mathrm{cp}}\right)$ of a polymer solution is correlated with the polymerization degree as:

$$
\frac{T_{\theta}}{T_{\text {cp }}}=1+\frac{1}{\psi}\left(\frac{1}{\sqrt{N}}-\frac{1}{2 N}\right)
$$

where $T_{\theta}$ is Flory's theta temperature and $\psi$ is the entropy parameter ${ }^{30)}$. Clearly, $T_{\text {cp }}$ is not equal to the $T_{\mathrm{c}}$ measured herein. In a previous paper, however, we reported that the $T_{\mathrm{c}}$ of the aqueous solution of PEO-PPO AMB copolymers is insensitive to the polymer concentration above $T_{\mathrm{cp}}$, which is located at ca. $0.3 \mathrm{wt} \%{ }^{23)}$. Thus, the $T_{\mathrm{c}}$ measured for the $1.5 \mathrm{wt} \%$ aqueous solution of the copolymers is expected to be close to the $T_{\mathrm{cp}}$. The intercept of the solid line in the inset gives a value of $39^{\circ} \mathrm{C}$, which corresponds to the $T_{\theta}$ of the system. In previous papers, we reported that the micellization temperature of $\left(\mathrm{EO}_{220} \mathrm{PO}_{33}\right)_{6}$ is around $41-50^{\circ} \mathrm{C}^{20)}$ and the second virial coefficient, $A_{2}$, of $\left(\mathrm{EO}_{220} \mathrm{PO}_{33}\right)_{8}$ approaches zero around $50^{\circ} \mathrm{C}^{23)}$. The results shown here imply that the Shultz-Flory theory is applicable even to PEO-PPO AMB copolymers.

\section{Conclusion}

We investigated the effect of the molecular weight on the $T_{\mathrm{c}}$ of aqueous solutions of PEO-PPO AMB copolymers with various molecular weights. The PEO-PPO AMB copolymers were obtained by precipitation fractionation. The $T_{\mathrm{c}}$ of the aqueous solution of the PEO-PPO AMB copolymer decreases as the $M_{\mathrm{n}}$ increases. The results imply that the Shultz-Flory theory is applicable to the PEO-PPO AMB copolymer/water system.

\section{Acknowledgment}

This work was supported by the Grant-in-Aid for Scientific Research (C) (No. 26410137).

\section{References}

1) Kobayashi, J.; Okano, T. Design of temperature-responsive polymer-grafted surfaces for cell sheet preparation and manipulation. Bull. Chem. Soc. Jpn. 92, 817-824(2019).

2) Rikiyama, K.;Sanada, Y.; Watanabe, K.; Aida, M.; Katsumoto, Y. Unimer structure and micellization of poly (ethylene oxide)-stereocontrolled poly ( $N$-isopropylacrylamide) alternating multiblock copolymers in aqueous solution. Macromolecules 52, 7188-7196 (2019).

3) Lutz, J. F. A controlled sequence of events. Nat. Chem. 2, 84-85 (2010).

4) Keerl, M.; Richtering, W. Synergistic depression of volume phase transition temperature in copolymer microgels. Colloid Polym. Sci. 285, 471-474(2007).

5) Maeda, Y.; Yamabe, M. A unique phase behavior of random copolymer of $N$-isopropylacrylamide and $N, N$-diethylacrylamide in water. Polymer (Guildf) 50, 519$523(2009)$.

6) Engelis, N.G.; Anastasaki, A.; Nurumbetov, G.; Truong, N.P.; Nikolaou, V.; Shegiwal, A.; Whittaker, M.R.; Davis, 
T.P.; Haddleton, D.M. Sequence-controlled methacrylic multiblock copolymers via sulfur-free RAFT emulsion polymerization. Nat. Chem. 9, 171-178(2017).

7) Gody, G.; Barbey, R.; Danial, M.; Perrier, S. Ultrafast RAFT polymerization: Multiblock copolymers within minutes. Polym. Chem. 6, 1502-1511(2015).

8) Gody, G.; Maschmeyer, T.; Zetterlund, P. B.; Perrier, S. Rapid and quantitative one-pot synthesis of sequencecontrolled polymers by radical polymerization. Nat. Commun. 4, 1-9(2013).

9) Simula, A.; Nikolaou, V.; Anastasaki, A.; Alsubaie, F.; Nurumbetov, G.; Wilson, P.; Kempe, K.; Haddleton, D.M. Synthesis of well-defined $\alpha, \omega$-telechelic multiblock copolymers in aqueous medium: In situ generation of $\alpha, \omega$-diols. Polym. Chem. 6, 2226-2233 (2015).

10) Anastasaki, A.; Oschmann, B.; Willenbacher, J.; Melker, A.; Van Son, M.H.C.; Truong, N.P.; Schulze, M.W.; Discekici, E.H.; McGrath, A.J.; Davis, T.P.; Bates, C.M.; Hawker, C.J. One-pot synthesis of ABCDE multiblock copolymers with hydrophobic, hydrophilic, and semifluorinated segments. Angew. Chemie-Int. Ed. 56, 14483-14487 (2017).

11) Carroll, D.R.; Constantinou, A.P.; Stingelin, N.; Georgiou, T.K. Scalable syntheses of well-defined pentadecablock bipolymer and quintopolymer. Polym. Chem. 9, 3450-3454(2018).

12) Zhang, Q.; Anastasaki, A.; Li, G.Z.; Haddleton, A.J.; Wilson, P.; Haddleton, D.M. Sequence-controlled multiblock glycopolymers to inhibit DC-SIGN-gp120 binding. Angew. Chemie-Int. Ed. 52, 4435-4439 (2013).

13) Alsubaie, F.; Anastasaki, A.; Wilson, P.; Haddleton, D.M. Sequence-controlled multi-block copolymerization of acrylamides via aqueous SET-LRP at $0{ }^{\circ} \mathrm{C}$. Polym. Chem. 6, 406-417(2015).

14) Zhang, Q.; Collins, J.; Anastasaki, A.; Wallis, R.; Mitchell, D.A.; Becer, C.R.; Haddleton, D.M. Multiblock sequence-controlled glycopolymers via $\mathrm{Cu}(0)$-LRP following efficient thiol-halogen, thiol-epoxy and CuAAC reactions. Polym. Chem. 5, 3876-3883 (2014).

15) Determan, M.D.; Cox, J.P.; Seifert, S.; Thiyagarajan, P.; Mallapragada, S.K. Synthesis and characterization of temperature and $\mathrm{pH}$-responsive pentablock copolymers. Polymer (Guildf) 46, 6933-6946 (2005).

16) Determan, M.D.; Guo, L.; Thiyagarajan, P.; Mallapragada, S.K. Supramolecular self-assembly of multiblock copolymers in aqueous solution. Langmuir 22, 14691473(2006).

17) Peleshanko, S.; Anderson, K.D.; Goodman, M.; Determan, M.D.; Mallapragada, S.K.; Tsukruk, V.V. Thermoresponsive reversible behavior of multistimuli pluronic-based pentablock copolymer at the air-water interface. Langmuir 23, 25-30 (2007).

18) Lu, Y.; Chen, T.; Mei, A.; Chen, T.; Ding, Y.; Zhang, X.; Xu, J.; Fan, Z.; Du, B. Solution behaviors and micro- structures of PNIPAm-P123-PNIPAm pentablock terpolymers in dilute and concentrated aqueous solutions. Phys. Chem. Chem. Phys. 15, 8276-8286 (2013).

19) Zhou, Y.; Jiang, K.; Song, Q.; Liu, S. Thermo-induced formation of unimolecular and multimolecular micelles from novel double hydrophilic multiblock copolymers of $N, N$-dimethylacrylamide and $N$-isopropylacrylamide. Langmuir 23, 13076-13084 (2007).

20) Rikiyama, K.; Horiuchi, T.; Koga, N.; Sanada, Y.; Watanabe, K.; Aida, M.; Katsumoto, Y. Micellization of poly (ethylene oxide)-poly (propylene oxide)alternating multiblock copolymers in water. Polymer (Guildf) 156, 102-110 (2018).

21) Muraoka, T.; Shima, T.; Hamada, T.; Morita, M.; Takagi, M.; Kinbara, K. Mimicking multipass transmembrane proteins: Synthesis, assembly and folding of alternating amphiphilic multiblock molecules in liposomal membranes. Chem. Commun. 47, 194-196(2011).

22) Alexandridis, P.; Holzwarth, J.F.; Hatton, T.A. Micellization of poly (ethylene oxide)-poly (propylene oxide)-poly (ethylene oxide) triblock copolymers in aqueous solutions: Thermodynamics of copolymer association. Macromolecules 27, 2414-2425 (1994).

23) Horiuchi, T.; Sakai, T.; Sanada, Y.; Watanabe, K.; Aida, M.; Katsumoto, Y. Association behavior of poly (ethylene oxide)-poly (propylene oxide) alternating multiblock copolymers in water toward thermally induced phase separation. Langmuir 33, 14649-14656 (2017).

24) Francuskiewicz, F. Polymer Fractionation. Springer, $\operatorname{Berlin}(1994)$.

25) Saeki, S.; Kuwahara, N.; Nakata, M.; Kaneko, M. Upper and lower critical solution temperatures in poly (ethylene glycol) solutions. Polymer (Guildf) 17, 685-689 (1976).

26) Alexandridis, P.; Alan Hatton, T. Poly (ethylene oxide) poly (propylene oxide) poly (ethylene oxide) block copolymer surfactants in aqueous solutions and at interfaces: thermodynamics, structure, dynamics, and modeling. Colloids Surf. A 96, 1-46(1995).

27) Watanabe, R.; Takaseki, K.; Katsumata, M.; Matsushita, D.; Ida, D.; Osa, M. Characterization of poly $(N, N$-diethylacrylamide) and cloud points in its aqueous solutions. Polym. J. 48, 621-628(2016).

28) Tong, Z.; Zeng, F.; Zheng, X.; Sato, T. Inverse molecular weight dependence of cloud points for aqueous poly ( $N$-isopropylacrylamide) solutions. Macromolecules 32, 4488-4490 (1999).

29) Shultz, A.R.; Flory, P.J. Phase equilibria in polymersolvent systems. J. Am. Chem. Soc. 74, 4760 (1952).

30) Hamada, F.; Fujisawa, K.; Nakajima, A. Lower critical solution temperature in linear polyethylene- $n$-alkane systems. Polym. J. 4, 316-322(1973). 